\title{
BRDT is a novel regulator of eIF4EBP1 in renal cell carcinoma
}

\author{
PEI WAN ${ }^{*}$, ZHILIN CHEN ${ }^{*}$, WEIFENG ZHONG, HUIMING JIANG, \\ ZHICHENG HUANG, DONG PENG, QIANG HE and NANHUI CHEN \\ Meizhou People's Hospital (Huangtang Hospital), Meizhou, Guangdong 514031, P.R. China
}

Received March 25, 2020; Accepted August 24, 2020

DOI: $10.3892 / o r .2020 .7796$

\begin{abstract}
Among all types of kidney diseases, renal cell carcinoma (RCC) has the highest mortality, recurrence and metastasis rates, which results in high numbers of tumor-associated mortalities in China. Identifying a novel therapeutic target has attracted increasing attention. Bromodomain and extraterminal domain (BET) proteins have the ability to read the epigenome, leading to regulation of gene transcription. As an important member of the BET family, bromodomain testis-specific protein (BRDT) has been well studied; however, the mechanism underlying BRDT in the regulation of RCC has not been fully investigated. Eukaryotic translation initiation factor 4E-binding protein 1 (eIF4EBP1) is a binding partner of eIF4E that is involved in affecting the progression of various cancer types via regulating gene transcription. To identify novel regulators of eIF4EBP1, an immunoprecipitation assay and mass spectrometry analysis was performed in RCC cells. It was revealed that eIF4EBP1 interacted with BRDT, a novel interacting protein. In addition, the present study further demonstrated that BRDT inhibitors PLX51107 and INCB054329 blocked the progression of RCC cells, along with suppressing eIF4EBP1 and c-myc expression. Small interfering (si) RNAs were used to knock down BRDT expression, which suppressed RCC cell proliferation and eIF4EBP1 protein expression. In addition, overexpression of eIF4EBP1 partially abolished the inhibited growth function of PLX51107 but knocking down eIF4EBP1 improved the inhibitory effects of PLX51107. Furthermore, treatment with PLX51107 or knockdown of BRDT expression decreased c-myc expression at both the mRNA and protein levels, and attenuated its promoter activity, as determined by luciferase reporter assays. PLX51107 also significantly altered the interaction between the
\end{abstract}

Correspondence to: Dr Nanhui Chen, Meizhou People's Hospital (Huangtang Hospital), 63 Huang Tang Road, Meizhou, Guangdong 514031, P.R. China

E-mail:nanfee@163.com

${ }^{*}$ Contributed equally

Key words: renal cell carcinoma, bromodomain testis-specific protein, eukaryotic translation initiation factor $4 \mathrm{E}$-binding protein 1 , c-myc, gene transcription, targeted therapy c-myc promoter with eIF4EBP1 and significantly attenuated the increase of RCC tumors, accompanied by decreased c-myc mRNA and protein levels in vivo. Taken together, these data suggested that blocking of BRDT by PLX51107, INCB054329 or BRDT knockdown suppressed the growth of RCC via decreasing eIF4EBP1, thereby leading to decreased c-myc transcription levels. Considering the regulatory function of BET proteins in gene transcription, the present study suggested that there is a novel mechanism underlying eIF4EBP1 regulation by BRDT, and subsequently decreased c-myc in RCC, and further identified a new approach by regulating eIF4EBP1 or c-myc for enhancing BRDT-targeting RCC therapy.

\section{Introduction}

Among adults, renal cell carcinoma (RCC) is the most common type of renal tumor $(1,2)$. There are $>10,000$ deaths and 220,000 new cases diagnosed with RCC each year worldwide $(3,4)$. The number of deaths and diagnosed cases accounts for $\sim 40 \%$ oc cancers in China $(5,6)$. Data from the National Health Commission of the PRC suggested that RCC incidence is increasing, with a $95 \%$ increase in growth rate over the past 28 years (1990-2018) (7). To date, RCC has ranked in the top three malignant types of tumors in males (8). Recently, due to increased incorrect dietary habits, such as high salt diet, unfiltered water drinking and sugary drink consumption, accompanied by increasingly advanced cancer diagnosis, the mortality of RCC has markedly increased in China (9). However, the 5-year survival rate is low, at 25-35\% (10). Since the majority of patients are diagnosed at middle or late stages with local or remote invasion, the combination treatment of chemotherapy and molecular-targeted therapy are commonly utilized $(11,12)$. Thus, investigating novel target molecules that serve a critical role in tumor progression and studying their molecular mechanism will aid in identifying novel targets for anti-RCC treatment. Additionally, there is an urgent need to further research the development of RCC and find more effective therapeutic methods for patients with RCC.

Bromodomain and extraterminal domain (BET) proteins serve a role as essential epigenome regulators for gene transcription mediation $(13,14)$. Bromodomain-containing protein (BRD)2, BRD3, BRD4 and bromodomain testis-specific protein (BRDT) are members of this family protein (15). BRDT has been well studied, and is involved in signaling transduction, gene transcription and tumor progression $(16,17)$. BRDT was reported to recognize acetylated histones and 
recruit transcriptional complexes, such as elongation factors, and other regulators to facilitate transcription progression $(18,19)$. However, an increasing amount of evidence indicated that BRDT could activate gene transcription during various diseases, such as testicular pathologies and malignant tumors $(16,20,21)$. In addition, BET was demonstrated as an effective target for lymphoma, multiple myeloma and acute myeloid leukemia, as well as in solid tumors including lung cancer, liver cancer and ovarian cancer, since c-Myc, Fos-related antigen 1 (FOSL1) and IL-7R oncogenes have been reported to be act BET targets $(22,23)$. PLX51107, INCB054329 and I-BET151, which are currently developed BET target treatments, were reported to be effective for cancer therapy in clinical trials (24-29). However, the effect and molecular mechanism of BET suppression, and the association between BET and eIF4EBP1 have not yet been fully elucidated in RCC. Therefore, identifying the downstream signals that regulates its functions in RCC is urgently required, which would provide basic clinical knowledge for generating targeted medicine in RCC.

Eukaryotic translation initiation factor 4E binding protein 1 (eIF4EBP1) directly interacts with eukaryotic translation initiation factor 4E (eIF4E), which functions as an essential limiting component to recruit $40 \mathrm{~S}$ ribosomal subunits to the 5 ' end of mRNAs (30-32). Meanwhile, the association between proteins and eIF4E suppresses complex assembly and inhibits gene translation (33). eIF4EBP1 is phosphorylated in response to UV irradiation, insulin signaling and virus infection, and diseases including malignant tumors, leading to the disruption of eIF4E mRNA translation $(34,35)$. Previous studies demonstrated that eIF4EBP1 acts as a biomarker in ovarian cancer and hepatocellular carcinoma (36,37). eIF4EBP1 facilitates tumorigenesis, invasion, reappearance and multidrug resistance in various cell lines and mouse experiments (38-40). MicroRNA-125a and microRNA-125b inhibits ovarian cancer via repressing transcription of eIF4EBP1 (41). However, the advanced position regulators that support eIF4EBP1 expression or eIF4EBP1 partners are limited. Thus, the present study hypothesized that BRDT may act as a partner of eIF4EBP1, and thus, regulate eIF4EBP1 transcription.

Investigating new interaction partners of eIF4EBP1 indicates a candidate method for identifying novel drug targets for RCC. In the present study, BRDT was identified as a new interaction protein of eIF4EBP1in RCC cells. Furthermore, it was suggested that BRDT could regulate eIF4EBP1 levels via interacting with its promoter sequence, and BRDT inhibitors could regulate eIF4EBP1 transcription as well as RCC progression. Overall, the results of the present study revealed that BRDT and eIF4EBP1 may function as a potentially novel therapeutic targets and biomarkers.

\section{Materials and methods}

Reagents. The BRDT inhibitors PLX51107 (cat. no. S8739) and INCB054329 (cat. no. S8753) were purchased from Selleck Chemicals. Both were dissolved in DMSO at $10 \mathrm{mmol} / \mathrm{l}$, stored at $-80^{\circ} \mathrm{C}$ and diluted in DMSO just before use. Exfect transfection reagent (cat. no. T202) was purchased from Vazyme Biotech Co., Ltd. Polyclonal antibody against BRDT (cat. no. NBP1-88357) was purchased from Novus Biologicals,
Ltd. c-Myc (D3N8F; cat. no. 13987) and eIF4EBP1 (53H11; cat. no. 9644) rabbit monoclonal antibodies were both purchased from Cell Signaling Technology, Inc. Rabbit polyclonal antibody against $\beta$-actin (cat. no. 0407-3) was purchased from Huanan Biotechnology. DMSO was purchased from Sigma-Aldrich; Merck KGaA. NP40 lysates and western blotting reagents were all purchased from Beyotime Institute of Biotechnology.

Cell lines and cell treatment. 293T cells and human RCC cell lines ACHN, 769-P and 768-O were all obtained from American Type Culture Collection. All cells were maintained in DMEM (cat. no. 11995; Beijing Solarbio Science \& Technology Co., Ltd.) supplemented with 10\% FBS (cat. no. 10099-141; Gibco; Thermo Fisher Scientific Inc.) and $0.1 \mathrm{mg} / \mathrm{m}$ penicillin-streptomycin solution at $37^{\circ} \mathrm{C}$ in a humidified atmosphere containing $5 \% \mathrm{CO}_{2}$.

DNA plasmid construction. The eIF4EBP1 or BRDT open reading frame (ORF) was amplified by PCR derived from ACHN cells and inserted into a pcDNA3.1 vector (Invitrogen; Thermo Fisher Scientific,Inc.). The promoter region from positions $-1,100$ to +80 of eIF4EBP1 was amplified and inserted into a pGL3.0-basic vector (Promega Corporation) to generate the pGL3-eIF4EBP1 promoter plasmid.

Sulforhodamine B (SRB) assays. All cells were cultured in 96-well plates at a density of $3 \times 10^{3}$ cells/well. Cells were then treated with different concentrations $(0.5,1,2,4,8,10 \mu \mathrm{mol} / \mathrm{l})$ of PLX for $48 \mathrm{~h}$. Cells transfected with small interfering (si) RNAs targeting eIF4EBP1 or control siRNAs (siCon) for $36 \mathrm{~h}$ were re-seeded in 96 -well plates at $2 \times 10^{3}$ cells/well and further cultured for $120 \mathrm{~h}$, or re-seeded to 96-well plates at $3 \times 10^{3}$ cells/well and treated with reagents at $48 \mathrm{~h}$ for a further $72 \mathrm{~h}$. An SRB assay was used to count the cell number. Cells were seeded into six-well plates and transiently transfected with eIF4EBP1 siRNAs and control siRNAs for $48 \mathrm{~h}$. The cells were then re-seeded into 96-well plates for another 5 days and subjected to the SRB assay. The proliferation rate of cells was assessed based on previously reported methods (20). The $\mathrm{IC}_{50}$ was determined using GraphPad Prism (version 5.01; GraphPad Software, Inc.).

Reverse transcription-quantitative PCR (RT-qPCR). Total RNA from cells or tumors tissues was extracted following the manufacturers' protocols of the RNA extraction kit (cat. no. P1023; Beijing Solarbio Science \& Technology Co., Ltd.). RT of RNA and qPCR were performed using the High-Capacity RNA-to-cDNA ${ }^{\mathrm{TM}}$ kit (Applied Biosystems; Thermo Fisher Scientific, Inc.) according to the manufacturer's protocol. All qPCR experiments were performed in triplicate using the ChamQ SYBR Color qPCR Master Mix (Vazyme Biotech Co., LTd.) on an ABI Prism 7500 sequence detection system (Applied Biosystems; Thermo Fisher Scientific, Inc.). The fold-change of target gene transcription was determined using the $2^{-\Delta \Delta \mathrm{Cq}}$ method (42). The following thermocycling conditions were used for the qPCR: Initial denaturation at $95^{\circ} \mathrm{C}$ for $5 \mathrm{~min} ; 40$ cycles of $95^{\circ} \mathrm{C}$ for $10 \mathrm{sec}$ and $60^{\circ} \mathrm{C}$ for $30 \mathrm{sec}$; and a final step at $95^{\circ} \mathrm{C}$ for $15 \mathrm{sec}, 60^{\circ} \mathrm{C}$ for $1 \mathrm{~min}$ and $95^{\circ} \mathrm{C}$ for $15 \mathrm{sec}$. The following primer pairs were used for the 
Table I. List of immunoprecipitated proteins.

IP: Anti-FLAG

\begin{tabular}{|c|c|c|c|}
\hline Accession no. & Name & Accession no. & Name \\
\hline NP-001017963.2 & Heat shock protein $90 \alpha$ family class member 1 & NP-001014431 & AKT serine/threonine kinase 1 \\
\hline NP-002145.3 & Heat shock $70 \mathrm{kDa}$ protein 4 & NP-001158095.1 & Argonaute RISC catalytic component 2 \\
\hline NP-001092.1 & $\operatorname{Actin} \beta(\mathrm{ACTB})$ & NP-997072.2 & Bromodomain testis associated protein \\
\hline NP-003371.2 & Vimentin (Homo sapiens) & NP-004086.1 & $\begin{array}{l}\text { Eukaryotic translation initiation factor } \\
\text { 4E binding protein } 1\end{array}$ \\
\hline AAA91576.1 & $\alpha$-tubulin & NP-001017963.2 & $\begin{array}{l}\text { Heat shock protein } 90 \alpha \text { family class } \\
\text { member } 1\end{array}$ \\
\hline NP-002037.2 & Glyceraldehyde-3-phosphate dehydrogenase & NP-000042.3 & ATM serine/threonine kinase \\
\hline
\end{tabular}

qPCR: BRDT (GenBank accession. no. NM-207189) forward, 5'-ATCAGACCACACCTTCACATG-3' and reverse, 5'-AGA GCTGTTCAGAATCACCTG-3'; eIF4EBP1 (GenBank accession. no. NM-004095.4) forward, 5'-ACCTGTGACCAAAAC ACCC-3' and reverse, 5'-TCAAACTGTGACTCTTCACCG-3'; c-myc (GenBank accession. no. NM_001354870) forward, 5'-CCAAGCTCGTCTCAGAGAAG-3' and reverse, 5'-GAT GCACTCTGAGGCGGCGG-3' and GAPDH (GenBank accession. no. NM-002046.7) forward, 5'-AATCCCATCACC ATCTTCCAG-3' and reverse, 5'-AAATGAGCCCCAGCC TTC-3'. Primers were synthesized by Sangon Biotech Co., Ltd.

Immunoprecipitation (IP) and mass spectrophotometry $(M S)$. To identify new binding partners of eIF4EBP1, ACHN cells were cultured in two $5-\mathrm{cm}$ dishes and transfected with $6 \mu \mathrm{g}$ eIF4EBP1 plasmids and control FLAG plasmids (cat. no. 635688, Clontech Laboratories, Inc.) using Exfect transfection reagent according to the manufacturer's instructions. After $48 \mathrm{~h}$, transfected cells were collected for lysis with $\mathrm{NP} 40$ buffer at $4^{\circ} \mathrm{C}$ for $2-4 \mathrm{~h}$. Total protein was determined using a bicinchoninic acid (BCA) Protein Determination kit (Beyotime Institute of Biotechonology). Proteins were centrifuged at $12,000 \mathrm{x} \mathrm{g}$ at $4^{\circ} \mathrm{C}$ for $10 \mathrm{~min}$ for the subsequent IP assay. A total of $1 \mu \mathrm{g}$ eIF4EBP1 antibody (cat. no. 9644; Cell Signaling Technology, Inc.) or FLAG antibody (cat. no. 14793; Cell Signaling Technology, Inc.) per $100 \mu \mathrm{g}$ total protein was used for IP for at least $2 \mathrm{~h}$ with protein A/G beads (Santa Cruz Biotechnology, Inc.) at $4^{\circ} \mathrm{C}$. Finally, beads were collected via centrifugation at $2,000 \mathrm{~g}$ at $4^{\circ} \mathrm{C}$ for $5 \mathrm{~min}$ and washed three to five times using NP40 buffer. Immunoprecipitated proteins were analyzed by MS (Table I).

Western blotting. Protein samples were prepared as described above. Protein concentrations were determined using a BCA Protein Determination kit. Equivalent amounts $(100 \mu \mathrm{g})$ of cell lysates were subjected to $15 \%$ SDS-PAGE and then transferred to PVDF membranes (Beijing Solarbio Science
\& Technology Co., Ltd.). Following blocking with 5\% bovine serum albumin (cat. no. A602449; Sangon Biotech Co., Ltd.) in phosphate-buffered saline (PBS) containing $0.1 \%$ Tween-20 (PBS-T) for $30 \mathrm{~min}$ at $25^{\circ} \mathrm{C}$, the membranes were incubated with primary antibodies $(1: 1,000)$ for $12 \mathrm{~h}$ at $4^{\circ} \mathrm{C}$ with gentle agitation. This was followed by incubation with HRP-conjugated goat anti-mouse IgG or goat anti-rabbit IgG (1:10,000; cat. nos. K0038M-HRP and SE134; Beijing Solarbio Science \& Technology Co., Ltd.) at room temperature for $45 \mathrm{~min}$. Finally, chemiluminescent signals were scanned and analyzed using Amersham Imager 600 (GE Healthcare).

siRNA transfection. To efficiently knock down BRDT and eIF4EBP1, the present study designed two BRDT siRNA (5'-UCTGCCAAGUCGACAAACAGCUAUU-3' and 5'-GCC AAGUCGACAAACAGCUAUUAUU-3'), two eIF4EBP1 siRNA (5'-GAGTCACAGTTTGAGATGGACATTT-3' and 5'-AGTCACAGTTTGAGATGGACATTTA-3) and a luciferase siRNA control sequence (5'-CAGGCCATGACAATG CTCCTGACAA-3') (all synthesized by Genepharm, Inc). A total of $100 \mathrm{nmol} / 1$ siRNAs were transfected into ACHN, 769-P or 768-O cells for $48 \mathrm{~h}$ using Exfect transfection reagent.

Luciferase reporter assay. ACHN, 769-P and 768-O cells were cultured in 24-well plates and transfected with pGL3-eIF4EBP1 and pRL-TK (Promega Corporation) using Exfect transfection reagents for $24 \mathrm{~h}$, and then exposed to $8 \mu \mathrm{mol} / \mathrm{l} \mathrm{BET}$ inhibitors for another $24 \mathrm{~h}$. The cells were subsequently collected for analysis according to the instructions of the Dual Luciferase Reporter Assay system (cat. no. E1910; Promega Corporation). The Renilla vector pRL-TK was used to normalize the transfection efficiency.

Chromatin IP (ChIP) assay. All cells (ACHN, 769-P and 768-O) were cultured in $5-\mathrm{cm}$ dishes and exposed to $8 \mu \mathrm{mol} / 1 \mathrm{BET}$ inhibitors for $24 \mathrm{~h}$, then collected for the ChIP assay according to the instructions of the ChIP assay kit 

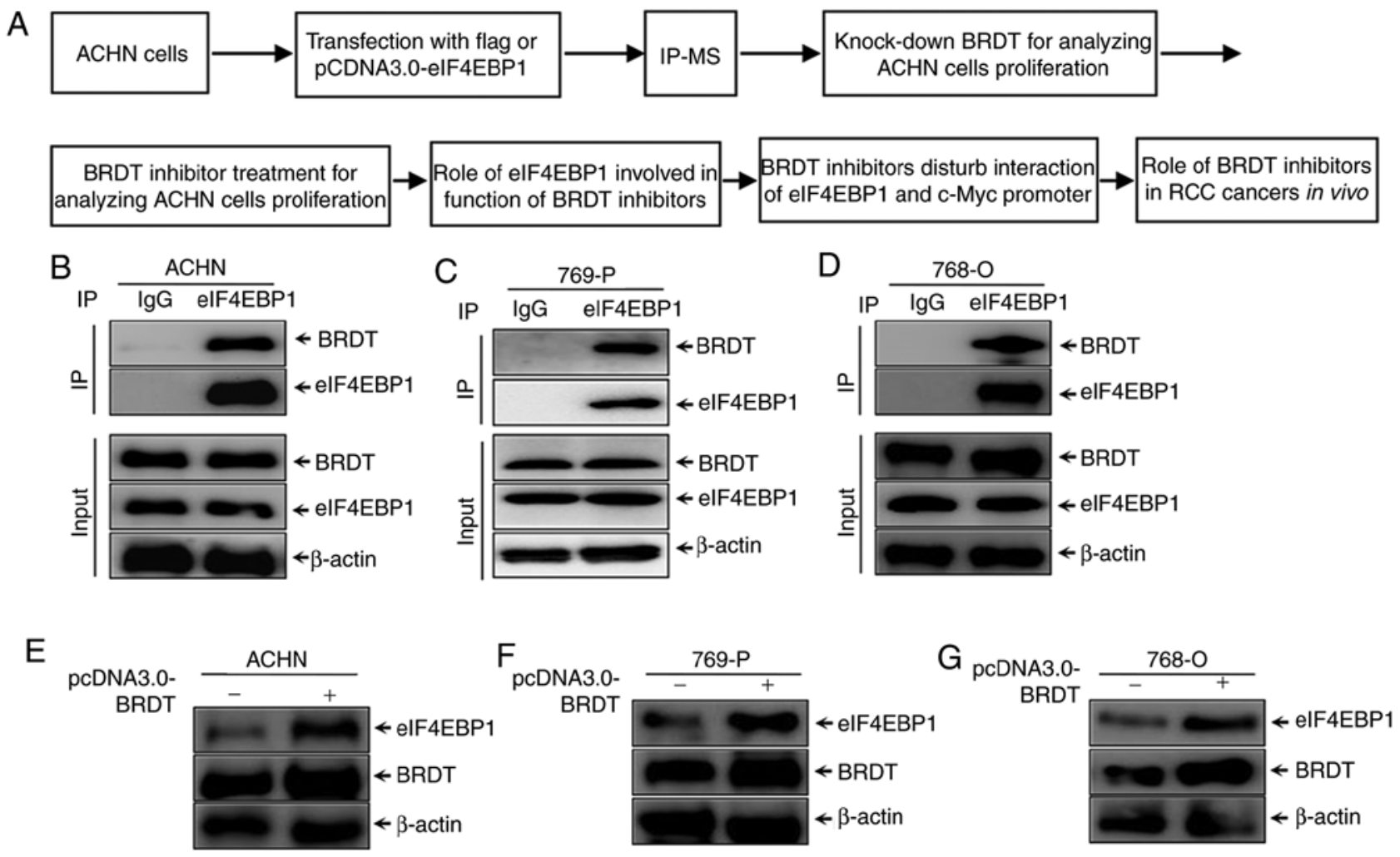

Figure 1. BRDT is a novel binding partner of eIF4EBP1. (A) Experimental workflow diagram. ACHN, 769-P and 768-O cells were cultured and transfected with eIF4EBP1 overexpression plasmids or control plasmids for $48 \mathrm{~h}$. Immunoprecipitation using anti-BRDT or IgG were performed in (B) ACHN, (C) 769-P and (D) 768-O cells, and subsequently subjected to western blotting using the indicated antibodies. (E) ACHN, (F) 769-P and (G) 768-O cells were transiently transfected with pCDNA3.1-BRDT for $36 \mathrm{~h}$, and then, the cells were lysed with NP40 buffer and collected for western blotting using the indicated antibodies. $\beta$-actin was used as the loading control. IP, immunoprecipitation; BRDT, bromodomain testis-specific protein; eIF4EBP1, eukaryotic translation initiation factor $4 \mathrm{E}$-binding protein 1.

(cat. no. P2078; Beyotime Institute of Biotechnology). Briefly, in order to crosslink proteins to DNA, whole cells were first fixed with $2 \%$ formaldehyde for $5 \mathrm{~min}$ at room temperature. Next, sonication was performed to cut the cross-linked DNA for $1 \mathrm{~h}$ at $4^{\circ} \mathrm{C}$ five times on the Qsonica Q800R3 sonicator (Aoran Biotechnology Co., Ltd.). For the control, 1/10 volume of total samples were used. eIF4EBP1 antibody or IgG antibody (cat. no. 0806-1; Hangzhou Huaan Biotechnology Co., Ltd.) was used for IP in samples. The immunoprecipitated complexes were washed three to five times with NP40 buffer and subjected to RT-qPCR.

Xenograft nude mouse model and treatments. The Institutional Animal Care and Use Committee of Sun Yat-sen University approved all animal experiments. The Model Animal Research Center of Sun Yat-sen University provided 18 6-week-old female athymic (nu/nu) mice (weight, $\sim 18 \mathrm{~g}$ ). All mice were raised in specific pathogen-free conditions and had ad libitum access to food and water in 40-60\% humidity and 10/14-h light/dark cycle at $27^{\circ} \mathrm{C}$. ACHN cells were cultured at a density of $5 \times 10^{5}$ cells $/ \mathrm{ml}$ in serum-free DMEM. Once tumors reached a size of $\sim 100 \mathrm{~mm}^{3}$, all the 18 mice were randomized into three groups ( $\mathrm{n}=6$ in each group) and treated with BET inhibitors $(100 \mathrm{mg} / \mathrm{kg} /$ day $)$ via oral gavage. Tumor volumes were measured every 2 days. The mice were sacrificed by injection with $150 \mathrm{mg} / \mathrm{kg}$ barbiturate at the end of the 14-day treatment or when the tumor diameter nearly reached $2 \mathrm{~cm}$. Respiratory arrest was validated using a ventilator and absence of heartbeat was determined by an electrocardiographic system to confirm death after euthanasia. After euthanizing, the tumors were removed and weighed, homogenized, and subjected to RT-qPCR and western blot analysis.

Statistical analysis. All results were collected from at least three independent repeats. Data were analyzed using SPSS 19.0 (IBM Corp.) and presented as the mean \pm SD. Statistical significance between datasets were analyzed by one or two-way ANOVA analysis followed by Bonferroni's post hoc test. $\mathrm{P}<0.05$ was considered to indicate a statistically significant difference.

\section{Results}

BRDT interacts with eIF4EBPI. The present study aimed to identify new interaction proteins of eIF4EBP1, thereby enabling further understanding the regulatory mechanisms of eIF4EBP1. The diagram of this study process is shown in Fig. 1A. ACHN cells were transfected with pCDNA3.0-eIF4EBP1 for IP-MS to identify interaction partners of eIF4EBP1. Next, the function of BRDT involved in ACHN cell proliferation was further analyzed. Finally, the molecular mechanism of BRDT inhibitors regulated by eIF4EBP1 and the role of BRDT inhibitors in RCC cancer growth were further analyzed. An IP assay of eIF4EBP1 in RCC cell lines was performed in the present 

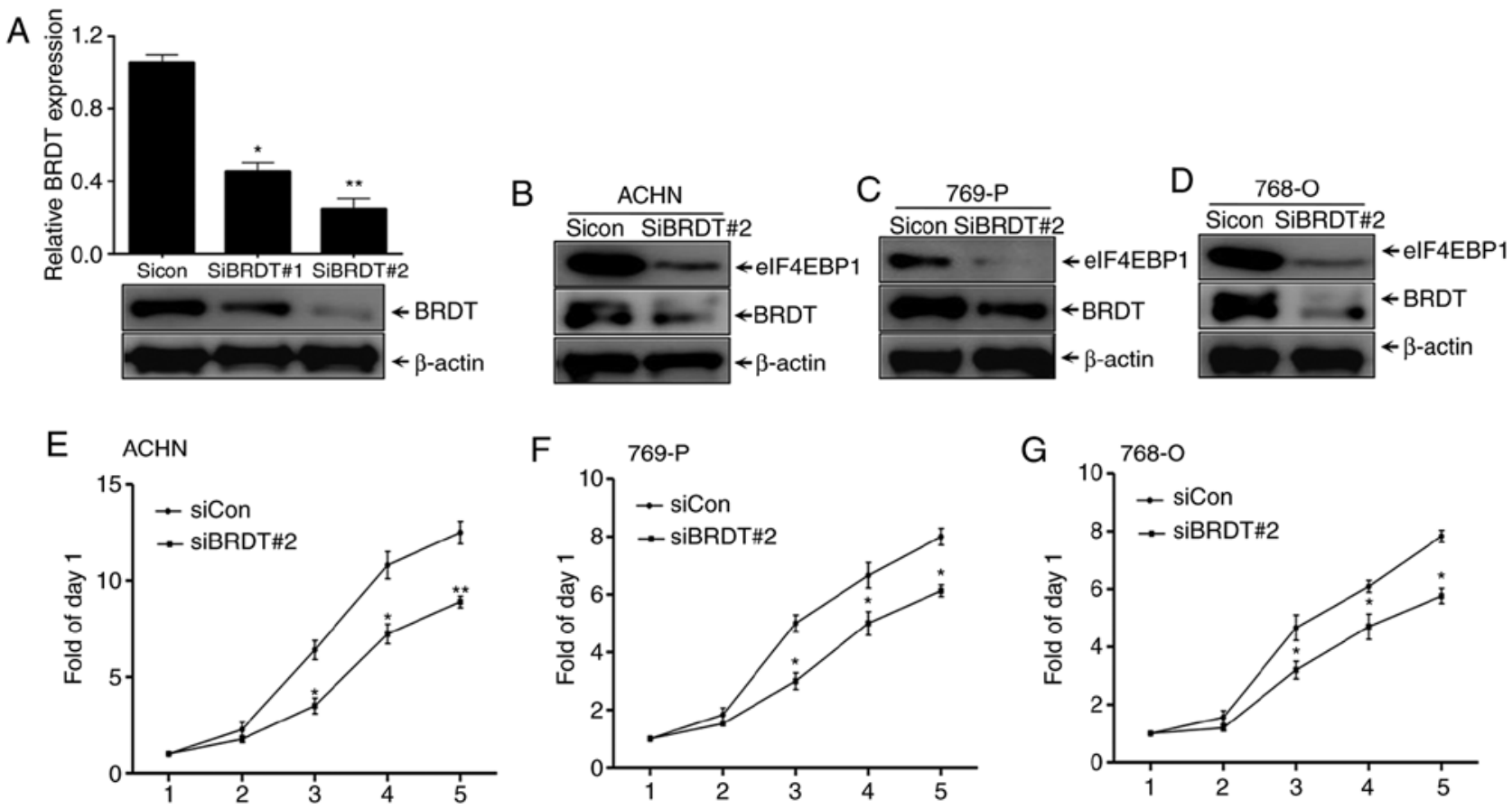

Figure 2. Silencing of BRDT inhibits the growth of renal cell carcinoma and suppresses eIF4EBP1 expression. (A) 293T cells were transiently transfected with two different siRNAs as well as with control siRNA for $48 \mathrm{~h}$. The cells were lysed with NP40 buffer for western blotting with the indicated antibodies. Efficient silencing of BRDT with siBRDT\#2 was performed in (B) ACHN, (C) 769-P and (D) 768-O cells for $48 \mathrm{~h}$. The cells were lysed with NP40 buffer for western blotting with the indicated antibodies. $\beta$-actin was used as the loading control. (E) ACHN, (F) 769-P and (G) 768-O cells were seeded in six-well plates and transiently transfected with siBRDT\#2 for $24 \mathrm{~h}$. The cells were then re-seeded into 96 -well plates for another $120 \mathrm{~h}$ and subjected to an SRB assay. Points indicate the mean of three experimental repeats. Bars represent the standard deviation. " $\mathrm{P}<0.05$ and ${ }^{* *} \mathrm{P}<0.01$ vs. siCon. siRNA, small interfering RNA; SRB, sulforhodamine B; BRDT, bromodomain testis-specific protein; eIF4EBP1, eukaryotic translation initiation factor 4E-binding protein 1; siCon, control siRNA.

study. ACHN cells were transfected with eIF4EBP1 plasmid for $48 \mathrm{~h}$. Proteins that were precipitated by eIF4EBP1 were identified by MS (performed by Applied Protein Technology, Shanghai, China). Meanwhile, samples were immunoprecipitated with FLAG antibody as the control. The indicated identified proteins and negative control proteins are listed in Table I. To further confirm the mass spectrometry results and the association between eIF4EBP1 and BRDT, co-IP was re-performed with endogenous eIF4EBP1 in ACHN cells and 769-P and 768-O whole cell lysates. IgG antibody was used as the negative control. The results, as presented in Fig. 1B-D, demonstrated that BRDT interacts with eIF4EBP1 endogenously in RCC cells. To further investigate the effect of BRDT on eIF4EBP1 expression, western blotting was used to analyze the protein levels of eIF4EBP1 following transfection of BRDT in RCC cell lines. The results presented in Fig. 1D-F suggested that eIF4EBP1 expression was markedly increased by ectopic expression of BRDT in RCC cell lines. Taken together, these results suggested that BRDT was identified as a novel interaction partner of eIF4EBP1 and increased eIF4EBP1 expression in RCC cell lines.

Silencing BRDT, together with suppressed eIF4EBPI expression, inhibits $R C C$ proliferation. To elucidate the mechanism underlying the effects of BRDT on eIF4EBP1 expression, the present study first assessed the regulation of eIF4EBP1 by interfering with BRDT expression. Two siRNAs that targeted different regions of BDRT were used, which, along with the control siRNA, were individually transfected into ACHN cells for $48 \mathrm{~h}$. Whole cell lysates were collected for western blotting. It was revealed that the interference efficiency of siRNA\#2 targeting BRDT was nearly $80 \%$ (Fig. 2A), indicating that BRDT was successfully silenced. The present study also revealed that eIF4EBP1 protein expression levels were decreased by BRDT knockdown in the RCC cell lines, ACHN, 769-P and 768-O (Fig. 2B-D). In addition, SRB assays suggested that knockdown of BRDT expression significantly blocked the proliferation of ACHN, 769-P and 768-O cells compared with the siRNA control group (Fig. 2E-G). Overall, these data suggested that inhibition of eIF4EBP1 expression may the due to knocking down BRDT.

BRDT inhibitors suppress eIF4EBPI expression and RCC proliferation. BRDT inhibitors, including PLX51107 and INCB054329, have been demonstrated to suppress the progression of lung cancer cells, bladder cancer cells and intestinal cancer cells $(24,25)$. The present study first analyzed the function of PLX51107 and INCB054329 on various RCC cell lines. SRB assays indicated that PLX51107 significantly inhibited the proliferation of ACHN, 769-P and 768-O cells in a dose-dependent manner (Fig. 3A). INCB054329 also exhibited similar results (Fig. 3B). The c-myc gene is a downstream target of PLX51107 and INCB054329 (43-45). The results in Fig. 3C and D show that the BET inhibitors PLX51107 and INCB054329, markedly decreased c-myc and eIF4EBP1 expression in a dose-dependent manner in RCC cell lines, ACHN, 769-P and 768-O cells, which demonstrated that eIF4EBP1 expression was significantly decreased by BRDT inhibitors PLX51107 and INCB054329. Altogether, these results suggested that RCC 
A
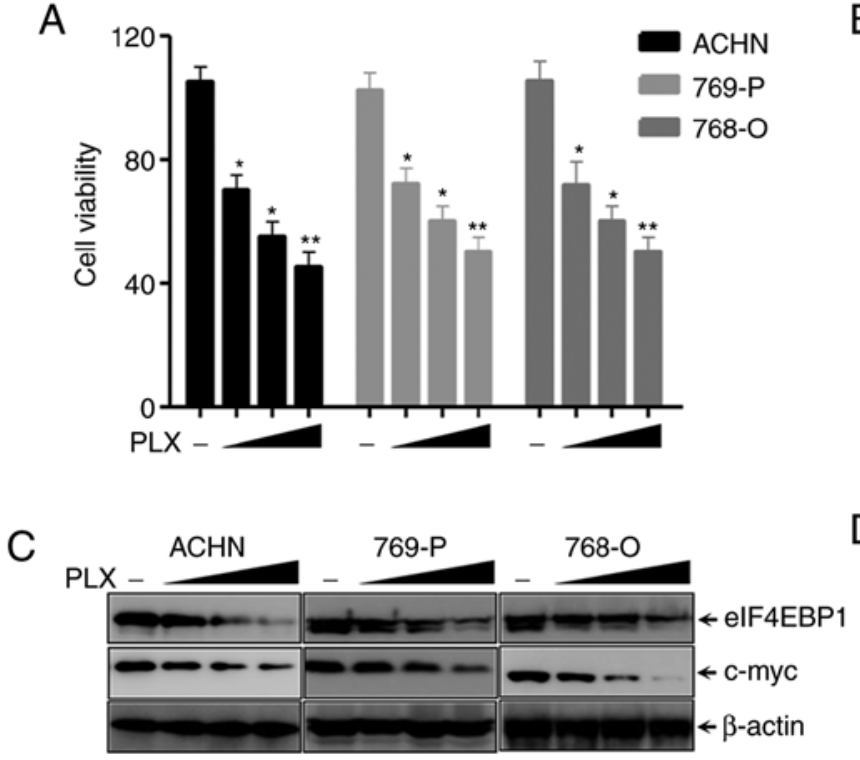
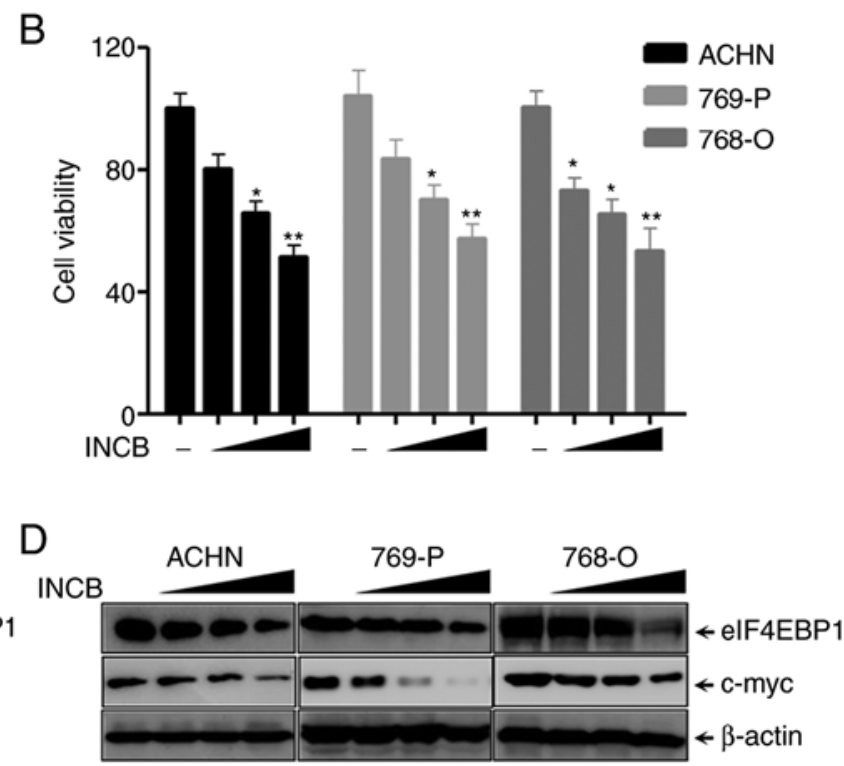

Figure 3. Bromodomain and extraterminal domain inhibitors suppresses renal cell carcinoma cell proliferation and eIF4EBP1 expression. ACHN, 769-P and 768-O cells were treated with different concentrations of (A) PLX51107 or (B) INCB054329 for 3 days and subjected to an SRB assay. ACHN, 769-P and 768-O cells were treated with 4,7 and $10 \mu \mathrm{mol} / 1$ (C) PLX51107 or (D) INCB054329 as indicated for $36 \mathrm{~h}$. Cells were lysed for western blotting with the indicated antibodies. $\beta$-actin was used as the loading control. Points indicate the mean of three experimental repeats. Bars represent the standard deviation. ${ }^{*} \mathrm{P}<0.05$ and ${ }^{* *} \mathrm{P}<0.01$ vs. untreated control. -, untreated control groups; SRB, sulforhodamine B; PLX, PLX51107; INCB, INCB054329; eIF4EBP1, eukaryotic translation initiation factor $4 \mathrm{E}-$ binding protein 1.

proliferation and eIF4EBP1 expression were inhibited by BET inhibitors.

eIF4EBP1 affects the inhibitory function of PLX51107 in RCC. The role of eIF4EBP1 in affecting the growth inhibitory function of PLX51107 and INCB054329 in RCC cell lines, ACHN, 769-P and 768-O cells, was further evaluated. Since the effect of PLX51107 and INCB054329 was similar, PLX51107 was selected for these experiments. The three cell lines were transiently transfected with recombinant plasmids containing full length ORFs for eIF4EBP1 or control empty vector for $48 \mathrm{~h}$. The cells were lysed with NP40 buffer and subsequently separated via SDS-PAGE for western blotting with the indicated antibodies. eIF4EBP1 protein levels were markedly increased in pcDNA3.0-eIF4EBP1 groups compared with the empty vector groups, indicating that eIF4EBP1 was successfully expressed in the three cell lines (Fig. 4A). In addition, SRB assay results showed that overexpression of eIF4EBP1 significantly partially attenuated the growth inhibition of PLX51107 in the three cell lines compared with the empty vector groups.

To further confirm the effects of eIF4EBP1 on regulating PLX5114 inhibitory function, two siRNAs targeting different regions of eIF4EBP1 and control siRNA were designed. The three cell lines were transfected with the aforementioned siRNAs for $48 \mathrm{~h}$, and then subjected to western blotting with the indicated antibodies. The results revealed that eIF4EBP1 protein levels significantly decreased up to $70 \%$ with the different siRNAs in different cell lines, which was in contrast to the control siRNAs, suggesting an efficient knockdown (Fig. 4C). Furthermore, the SRB assay suggested that the suppression effects of PLX51107 on the growth of the cell lines increased in eIF4EBP1-silenced cells in a dose-dependent manner (Fig. 4D). Overall, these results demonstrated that PLX51107 suppressed the proliferation of RCC cells via inhibition of eIF4EBP1 expression, and eIF4EBP1 affected the inhibition of PLX51107 on RCC cells.

BRDT inhibitors decrease the interaction between eIF4EBPI and $c$-myc promoter. Due to decreased regulation of eIF4EBP1 expression assuming an essential role in mediating the growth inhibitory effect of PLX51107, it was hypothesized that eIF4EBP1 directly affects c-myc expression in RCC cells. The present study first analyzed the mRNA transcription levels of c-myc mediated by BRDT inhibitors, PLX51107 and INCB054329. As shown in Fig. 5A and B, the c-myc mRNA transcription levels significantly decreased upon treatment with PLX51107 and INCB054329 at 6 and $18 \mathrm{~h}$ in the three cell lines. Meanwhile, the RT-qPCR assay revealed that silencing BRDT expression also significantly decreased c-myc mRNA transcription levels compared with control siRNA groups (Fig. 5C), which is consistent with the results of si-eIF4EBP1 transfection (Fig. 5C). Next, the present study assessed the promoter activity of c-myc using dual-luciferase reporter assays. The pGL3-c-myc promoter plasmid and the control vector pGL3.0-basic were transfected into the three cells for $36 \mathrm{~h}$, and then treated with PLX51107 and INCB054329 for another $24 \mathrm{~h}$. The Renilla plasmid, used to normalize the transfection efficiency, was also co-transfected to the cells. As presented in Fig. 5D, treatment with the BRDT inhibitors, PLX51107 and INCB054329, could significantly decrease c-myc promoter activity in the three cell lines compared with controls, indicating that BET inhibitors suppressed c-myc transcription. In conclusion, these data demonstrated that BET inhibitors decreased c-myc transcription via inhibition of BRDT and eIF4EBP1.

To investigate the molecular mechanism underlying how BET inhibitors inhibit c-myc promoter activity, a ChIP assay using eIF4EBP1 antibody in the three cell lines was performed. The three cell lines were treated with PLX51107 for $24 \mathrm{~h}$. 
A
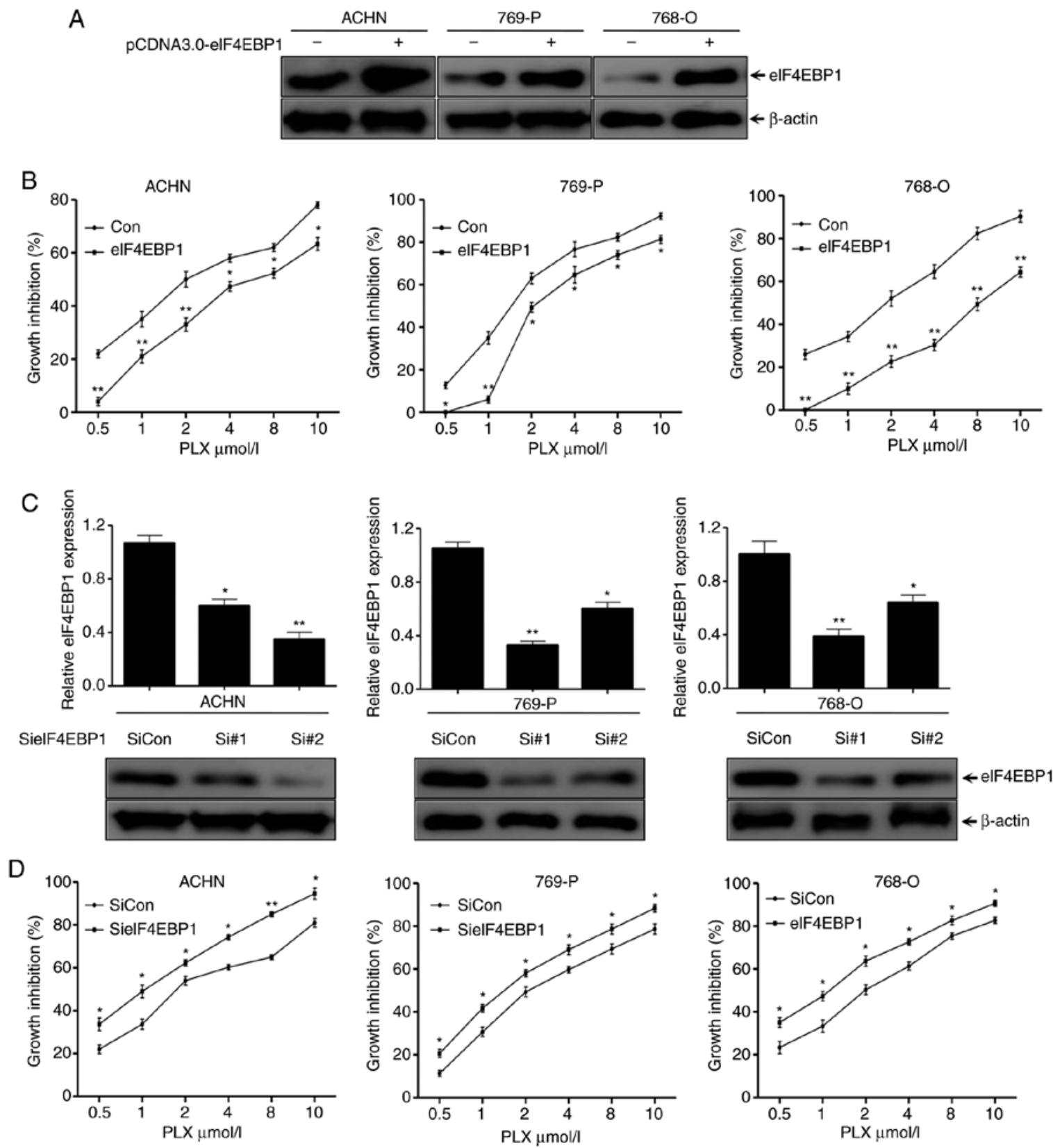

Figure 4. eIF4EBP1 affects the inhibitory function of PLX51107 in renal cell carcinoma. (A) ACHN, 769-P and 768-O cells were transiently transfected with pCDNA3.1-eIF4EBP1 plasmids or empty control plasmids for $48 \mathrm{~h}$ using Exfect transfection reagent, and then subjected to western blotting using the indicated antibodies. (B) The three cell lines were transfected with the indicated plasmids as aforementioned for $24 \mathrm{~h}$ and then re-cultured in 96 -well plates, treated with different concentrations of PLX51107 as indicated for another 3 days, and subjected to an SRB assay. (C) The three cell lines were transfected with two different siRNAs targeting two regions of eIF4EBP1 and the control siRNAs for $48 \mathrm{~h}$, and then subjected to western blotting with the indicated antibodies. (D) The three cell lines transfected with the indicated siRNAs of eIF4EBP1 or the control siRNAs for $24 \mathrm{~h}$ were re-seeded to 96 -well plates and treated with PLX at the indicated concentrations, and then subjected to an SRB assay. Data are representative of three independent experiments. Bars represent the standard deviation. ${ }^{*} \mathrm{P}<0.05$ and ${ }^{* *} \mathrm{P}<0.01$ vs. control groups. SRB, sulforhodamine $\mathrm{B}$; siRNA, small interfering RNA; PLX, PLX51107; siCon, control siRNA.

Whole cell lysates were used for the CHIP assay. The results in Fig. 5E and $\mathrm{F}$ showed that the PCR products of c-myc promoter were significantly decreased in the eIF4EBP1 antibody IP group compared with the control IgG group, implying that PLX51107 decreased the interaction of c-myc promoter with eIF4EBP1. These results suggested that PLX51107 inhibited eIF4EBP1 protein levels and the association of eIF4EBP1 with c-myc promoter, and inhibited subsequent c-myc transcription.

BET inhibitors suppresses ANCH tumor progression and c-myc protein levels in vivo. To further verify the underlying mechanism and function of BET inhibitors in RCC tumors and c-myc regulation, an ACHN xenograft nude mouse model in vivo experiment was established. PLX51107 (oral gavage, $100 \mathrm{mg} / \mathrm{kg} /$ day) and INCB054329 (oral gavage, $90 \mathrm{mg} / \mathrm{kg} / \mathrm{day}$ ) and negative control (oral gavage with physiological saline) were used to treat mice for 14 days ( $n=6$ in each group) (24). The tumor volume was significantly lower in both PLX51107- and INCB054329-treated groups compared with the control group (Fig. 6A). Meanwhile, the tumor weight significantly decreased in both PLX51107 and INCB054329 groups compared with the control group (Fig. 6B). The images of the tumors are presented in Fig. 6C. In addition, 

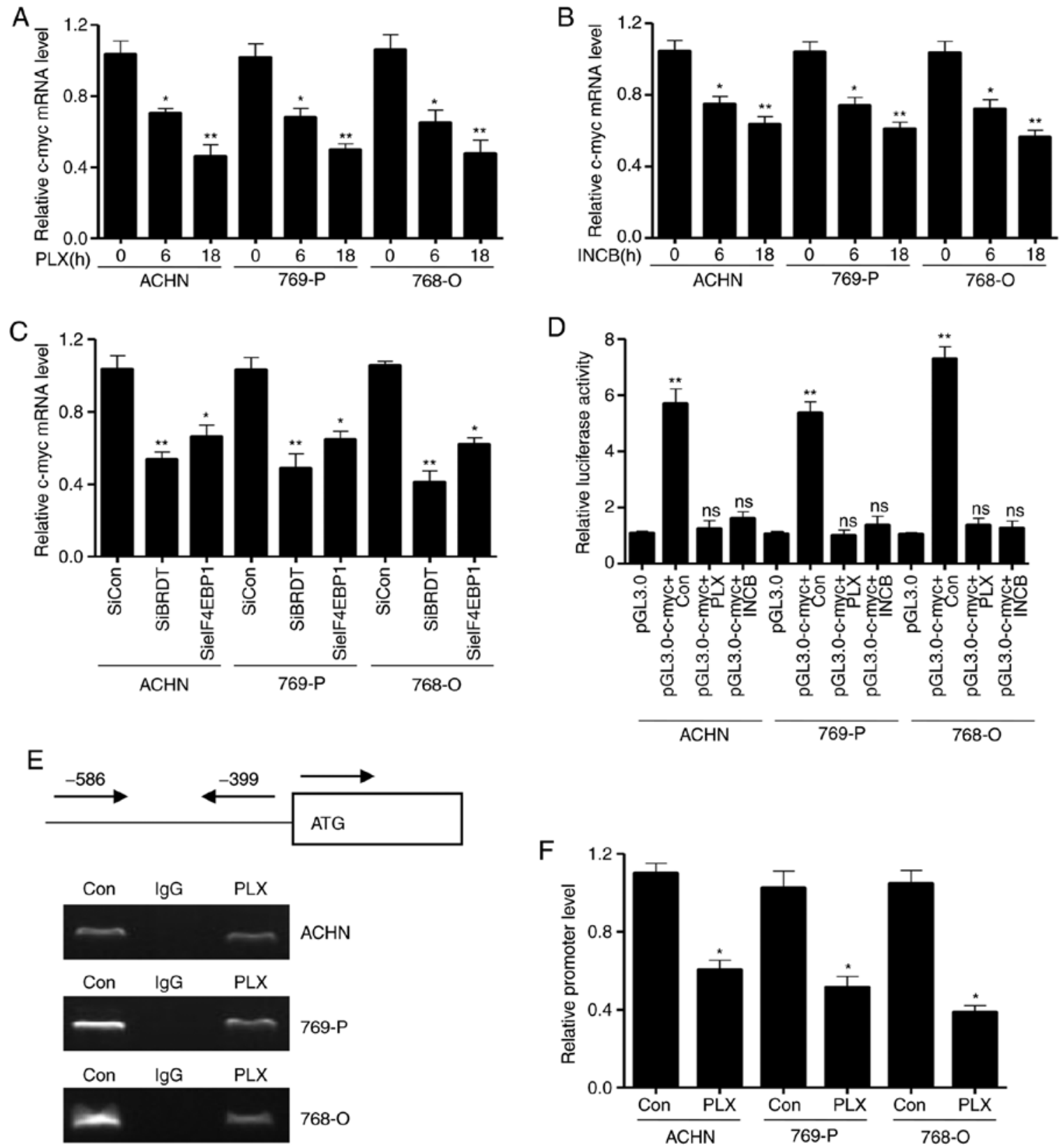

Figure 5. Bromodomain and extraterminal domain inhibitors decrease eIF4EBP1 associated with c-myc promoter. The three cell lines were treated with the indicated concentrations of (A) PLX51107 or (B) INCB054329 for different time periods (0, 6 and $18 \mathrm{~h}$ ) and subjected to RT-qPCR. (C) The three cell lines were transiently transfected with the indicated siRNAs or control siRNAs for $24 \mathrm{~h}$. Total RNA was extracted and subjected to RT-qPCR assay for detecting the c-myc mRNA transcription level. (D) The three cell lines were transiently transfected with c-myc promoter plasmid or the control vector using Exfect reagent and treated with the indicated concentrations of PLX51107 or INCB054329 for $36 \mathrm{~h}$. Renilla plasmids were co-transfected as the loading control. The cells were lysed and subjected to dual luciferase reporter assays. The three cell lines were treated with PLX51107 for $36 \mathrm{~h}$, and then subjected to chromatin immunoprecipitation using eIF4EBP1 antibody. The c-myc promoter was detected using primers designed from -586 to -399 pre-leading regions of the start site (0 is the ATG start site). The PCR products of c-myc promoter was analyzed by (E) and agarose gel electrophoresis and (F) qPCR. Data are representative of three independent experiments. Bars represent the standard deviation. ${ }^{*} \mathrm{P}<0.05$ and ${ }^{* *} \mathrm{P}<0.01$. RT-qPCR, reverse transcription-quantitative PCR; PLX, PLX51107; INCB, INCB054329; Con, control; siRNA, small interfering RNA; siCon, control siRNA; BRDT, bromodomain testis-specific protein; eIF4EBP1, eukaryotic translation initiation factor 4E-binding protein 1.

the transcription and protein levels of c-myc were determined by RT-qPCR and western blotting. The results in Fig. 6C showed that the mRNA transcription and protein levels of c-myc in vivo tumors treated with BET inhibitors were significantly lower compared with the control group tumors (Fig. 6D). Taken together, these results suggested that treatment with BRDT inhibitors PLX51107 and INCB054329 could inhibit RCC tumor progression and decrease c-myc expression in vivo.

\section{Discussion}

The present study revealed several results with regard to BRDT inhibition in the progression of RCC: i) BRDT-specific inhibitors, PLX51107 and INCB054329, inhibited the proliferation of various RCC cell lines; ii) BRDT was identified as a novel interaction partner of eIF4EBP1; iii) Expression of eIF4EBP1 was directly affected by BRDT; iv) BRDT 

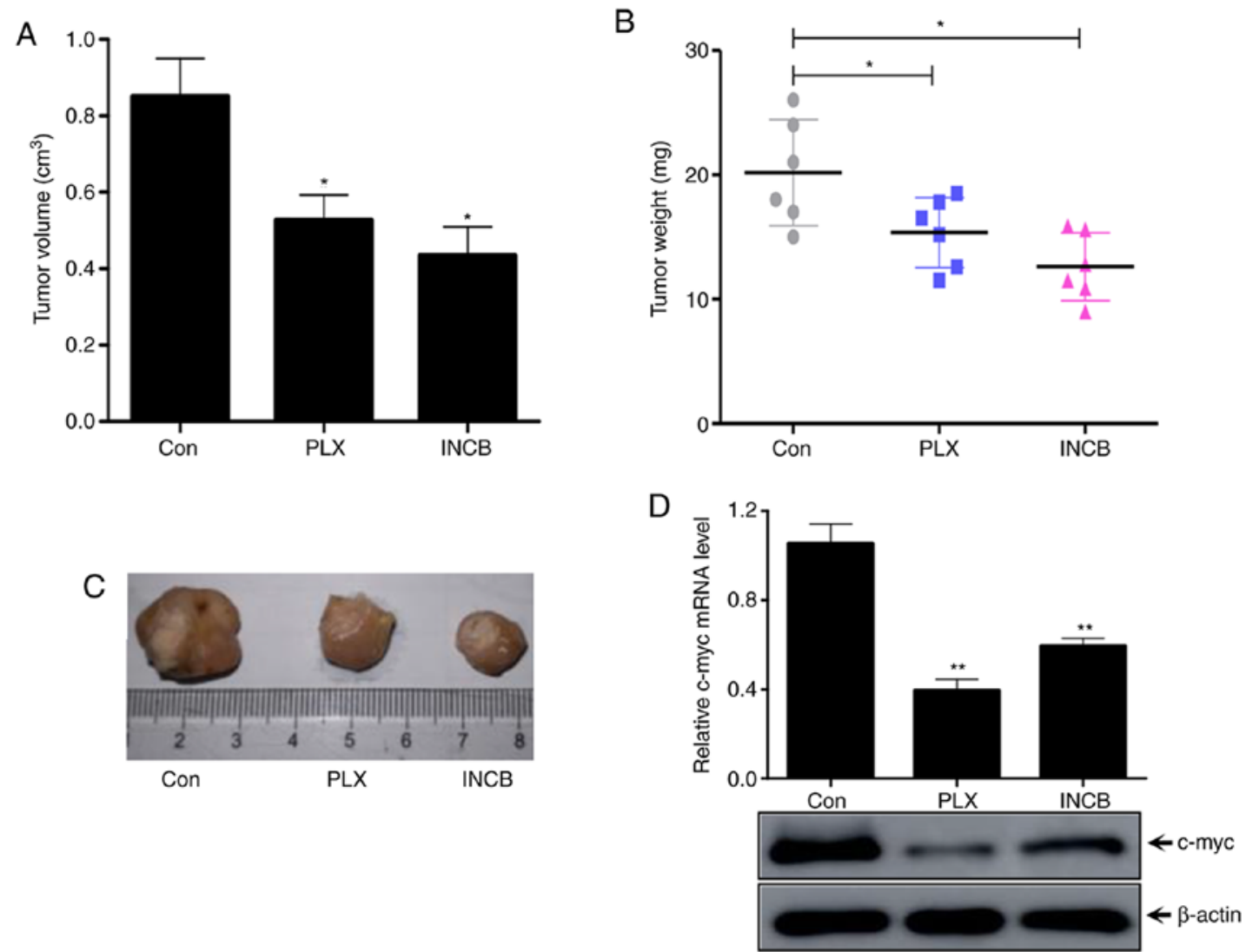

Figure 6. Bromodomain and extraterminal domain inhibitors inhibits renal cell carcinoma tumor growth and c-myc expression in vivo. ACHN cells were inoculated in the subcutaneous regions of nude mice. The mice were treated with $100 \mathrm{mg} / \mathrm{kg} / \mathrm{day}$ PLX51107 or $90 \mathrm{mg} / \mathrm{kg} / \mathrm{day}$ INCB054329 or the vehicle for 14 days ( $n=6$ for each group). The (A) volume and (B) weight of ACHN tumors were determined and calculated. (C) Images of the tumors. (D) Total RNA from tumors were isolated and subjected to reverse transcription-quantitative PCR and western blotting using the indicated antibodies to assess c-myc transcription and protein levels. Columns represent the mean of three independent experiments. Bars represent the standard deviation. ${ }^{*} \mathrm{P}<0.05$ and ${ }^{* *} \mathrm{P}<0.01$ vs. control. $\mathrm{PLX}$, PLX51107; INCB, INCB054329; Con, control.

regulated the binding of eIF4EBP1 with c-myc promoter; v) Knockdown of BRDT protein inhibited RCC cell proliferation and vi) BRDT inhibitors suppressed ACHN tumors growth in vivo. Targeting BET proteins was demonstrated to inhibit tumor growth in various types of cancer, including multiple myeloma, lymphoma, ovarian cancer, bladder cancer, castration-resistant prostate cancer and lung cancer $(46,47)$. BRD4, a family of BET proteins, was reported to function as a tumor suppressor in colon cancer and lung cancer (48). To the best of our knowledge, there have been no reports on the role of the BET family in RCC cell proliferation. The present study revealed that three RCC cell lines were sensitive to the BRDT inhibitors PLX51107 and INCB054329.

PLX51107 and INCB054329 are small molecular inhibitors that specifically target BRDT. PLX51107 and INCB054329 interact with the domain of BRDT that recognizes acetylated lysine and disassociates from chromatin, thereby blocking gene transcription $(24,25)$, which suggests that PLX51107 and INCB054329 may disrupt the interaction of BRDT with other regulators to block gene transcription during chromatin remodeling. Hence, PLX51107 and INCB054329 is thought to inhibit tumor progression during specific conditions (49-51). Suppression of c-Myc transcription was hypothesized to serve an important role in BRD4-induced suppression of tumor growth in malignant hematological diseases and solid tumors (52-54). In lung cancer, the BET inhibitor JQ1 demonstrated antitumor functions not only via suppression of c-myc, but also via downregulation of FOSL1 (55). The present study first identified that eIF4EBP1 acted as a novel binding partner with BRDT, and it was also revealed that c-myc and eIF4EBP1 expression was decreased by BRDT inhibitors or BRDT knockdown. These results provided an additional mechanism for the effects of BRDT in RCC.

In the present study, eIF4EBP1 was identified as a novel binding partner of BRDT and c-myc was a target of eIF4EBP1. The mRNA transcription and protein expression levels of c-myc were inhibited by BRDT inhibitors, PLX51107 and INCB054329, or when BRDT was silenced in RCC cell lines. This was also observed in a xenograft mouse model. Furthermore, overexpression of eIF4EBP1 significantly attenuated BRDT inhibitor suppression on cell proliferation, indicating that knockdown of eIF4EBP1 serves a role in the progression of RCC. eIF4EBP1 is an important interaction partner of eIF4E, which facilitates the restriction process during translation initiation (56). It was also reported to be upregulated in various types of tumors and promote cancer growth (57). The present study demonstrated that eIF4EBP1 downregulation significantly improved PLX51107-induced growth suppression of RCC, revealing a new approach for cancer therapy by co-targeting PLX51107 and BRDT protein.

In recent decades, alternative epigenetic regulation for gene expression has attracted an increasing amount of 
attention $(58,59)$. Targeting the downstream target of eIF4E, eIF4F or its binding partners is emerging as a potential treatment opportunity. The present study observed a decrease in c-myc mRNA expression following addition of BRDT inhibitors, and a decrease in c-myc promoter activity caused by BRDT inhibitors in a dual luciferase reporter assay, implying a mechanism of c-myc transcription mediation. The ChIP assay demonstrated that the association between c-myc promoter and eIF4EBP1 was significantly decreased by BRDT inhibitors, implying that BRDT inhibitors decreased c-myc expression via inhibition of eIF4EBP1 protein, and the binding of eIF4EBP1 with c-myc promoter and subsequent transcription. There is a possibility that BRDT may also bind with transcriptional factors or transcription regulatory proteins, or attract multi-complexes to modified chromatin to promote transcription (58).

In conclusion, the results of the present study suggested that targeting BRDT by PLX51107 and INCB054329, or BRDT-knockdown, suppressed RCC cell proliferation and tumor growth via releasing the binding of eIF4EBP1 from the c-myc promoter and decreasing subsequent c-myc mRNA transcription and protein expression. These results identified a novel molecular mechanism of BRDT-regulated eIF4EBP1 as well as c-myc in RCC tumors and demonstrated a new method of targeting both eIF4EBP1 and c-myc to support BRDT-targeted cancer therapy.

\section{Acknowledgements}

Not applicable.

\section{Funding}

The present study was supported by the Natural Science Foundation of Guangdong Province(grant no.2017A030307037).

\section{Availability of data and materials}

The datasets used and/or analyzed during the current study are available from the corresponding author on reasonable request.

\section{Authors' contributions}

PW, NC and ZC designed the experiments. PW performed the IP and CHIP assay. ZC designed the whole siRNA and performed the transfection. WZ and $\mathrm{HJ}$ performed the plasmid construction. PW and ZC performed the mice experiments. $\mathrm{ZH}$ and DP performed the dual luciferase reporter assay. $\mathrm{QH}$ performed the SBR assay. PW, NC and ZC analyzed the data. All authors read and approved the final manuscript.

\section{Ethics approval and consent to participate}

All the experiments was conducted based on the supervision and approval of the Institutional Animal Care and Use Committee of Sun Yat-sen University.

\section{Patient consent for publication}

Not applicable.

\section{Competing interests}

The authors declare that they have no competing interests.

\section{References}

1. Cella D, Grünwald V,Escudier B,Hammers HJ, George S, Nathan P, Grimm MO, Rini BI, Doan J, Ivanescu C, et al: Patient-Reported outcomes of patients with advanced renal cell carcinoma treated with nivolumab plus ipilimumab versus sunitinib (CheckMate 214): A randomised, phase 3 trial. Lancet Oncol 20: 297-310, 2019.

2. Powles T: Re: Nivolumab plus ipilimumab versus sunitinib in advanced renal-cell carcinoma. Eur Urol 74: 679-680, 2018.

3. Chevrier S, Levine JH,Zanotelli VR, Silina K, Schulz D, Bacac M, Ries CH, Ailles L, Jewett MA, Moch H, et al: An immune atlas of clear cell renal cell carcinoma. Cell 169: 736-749, 2017.

4. Song E, Song W, Ren M, Xing L, Ni W, Li Y, Gong M, Zhao M, Ma X, Zhang X and An R: Identification of potential crucial genes associated with carcinogenesis of clear cell renal cell carcinoma. J Cell Biochem 119: 5163-5174, 2018.

5. Wang Q, Ding H, He Y, Li X, Cheng Y, Xu Q, Yang Y, Liao G, Meng X, Huang C and Li J: NLRC5 mediates cell proliferation, migration, and invasion by regulating the wnt $/ \beta$-catenin signalling pathway in clear cell renal cell carcinoma. Cancer Lett 444: 9-19, 2019.

6. Zhang X, Yan L, Jiao W, Ren J, Xing N, Zhang Y, Zang Y, Wang J and $\mathrm{Xu} Z$ : The clinical and biological significance of MICA in clear cell renal cell carcinoma patients. Tumour Biol 37: 2153-2159, 2016.

7. Zhu H, Wang Z, Xu Q, Zhang Y, Zhai Y, Bai J, Liu M, Hui Z and Xu N: Inhibition of STAT1 sensitizes renal cell carcinoma cells to radiotherapy and chemotherapy. Cancer Biol Ther 13: 401-407, 2012.

8. Wozniak MB, Le Calvez-Kelm F, Abedi-Ardekani B, Byrnes G, Durand G, Carreira C, Michelon J, Janout V, Holcatova I, Foretova L, et al: Integrative genome-wide gene expression profiling of clear cell renal cell carcinoma in czech republic and in the United States. PLoS One 8: e57886, 2013.

9. Wu J, Wang H, Ricketts CJ, Yang Y, Merino MJ, Zhang H, Shi G, Gan H, Linehan WM, Zhu Y and Ye D: Germline mutations of renal cancer predisposition genes and clinical relevance in Chinese patients with sporadic, early-onset disease. Cancer 125: 1060-1069, 2019

10. Ghatalia P, Gordetsky J, Kuo F, Dulaimi E, Cai KQ, Devarajan K, Bae S, Naik G, Chan TA, Uzzo R, et al: Prognostic impact of immune gene expression signature and tumor infiltrating immune cells in localized clear cell renal cell carcinoma. J Immunother Cancer 7: 139, 2019.

11. Pal S, Gong J, Mhatre SK, Lin SW, Surinach A, Ogale S, Vohra R, Wallen $\mathrm{H}$ and George D: Real-World treatment patterns and adverse events in metastatic renal cell carcinoma from a large US claims database. BMC Cancer 19: 548, 2019.

12. Karner C, Kew K, Wakefield V, Masento N and Edwards SJ: Targeted therapies for previously treated advanced or metastatic renal cell carcinoma: Systematic review and network meta-analysis. BMJ Open 9: e24691, 2019.

13. Suarez-Alvarez B, Morgado-Pascual JL, Rayego-Mateos S, Rodriguez RM, Rodrigues-Diez R, Cannata-Ortiz P, Sanz AB, Egido J, Tharaux PL, Ortiz A, et al: Inhibition of bromodomain and extraterminal domain family proteins ameliorates experimental renal damage. J Am Soc Nephrol 28: 504-519, 2017.

14. McDaniel KF, Wang L, Soltwedel T, Fidanze SD, Hasvold LA, Liu D, Mantei RA, Pratt JK, Sheppard GS, Bui MH, et al: Discovery of N-(4-(2,4-Difluorophenoxy)-3-(6-methyl-7-oxo-6,7dihydro-1H-pyrrolo[2,3-c]pyridin-4-yl)phenyl)ethanesulfonamide (ABBV-075/Mivebresib), a potent and orally available bromodomain and extraterminal domain (BET) family bromodomain inhibitor. J Med Chem 60: 8369-8384, 2017.

15. Manterola M, Brown TM, Oh MY, Garyn C, Gonzalez BJ and Wolgemuth DJ: BRDT is an essential epigenetic regulator for proper chromatin organization, silencing of sex chromosomes and crossover formation in male meiosis. PLoS Genet 14: e1007209, 2018.

16. De Rijck J, de Kogel C, Demeulemeester J, Vets S, El Ashkar S, Malani N, Bushman FD, Landuyt B, Husson SJ, Busschots K, et al: The BET family of proteins targets moloney murine leukemia virus integration near transcription start sites. Cell Rep 5: 886-894, 2013. 
17. Dibenedetto AJ, Guinto JB, Ebert TD, Bee KJ, Schmidt MM and Jackman TR: Zebrafish brd2a and brd2b are paralogous members of the bromodomain-ET (BET) family of transcriptional coregulators that show structural and expression divergence. BMC Dev Biol 8: 39, 2008.

18. Wang L and Wolgemuth DJ: BET protein BRDT complexes with HDAC1, PRMT5, and TRIM28 and functions in transcriptional repression during spermatogenesis. J Cell Biochem 117: $1429-1438,2016$

19. Pivot-Pajot C, Caron C, Govin J, Vion A, Rousseaux S and Khochbin S: Acetylation-Dependent chromatin reorganization by BRDT, a testis-specific bromodomain-containing protein. Mol Cell Biol 23: 5354-5365, 2003.

20. Bourova-Flin E, Chuffart F, Rousseaux S and Khochbin S: The role of bromodomain testis-specific factor, BRDT, in cancer: A biomarker and a possible therapeutic target. Cell J 19: 1-8, 2017.

21. Barda S, Yogev L, Paz G, Yavetz H, Lehavi O, Hauser R, Doniger T, Breitbart $\mathrm{H}$ and Kleiman SE: BRDT gene sequence in human testicular pathologies and the implication of its single nucleotide polymorphism (rs3088232) on fertility. Andrology 2: 641-647, 2014

22. Suyama T, Shiraishi T, Zeng Y, Yu W, Parekh N, Vessella RL, Luo J, Getzenberg RH and Kulkarni P: Expression of cancer/testis antigens in prostate cancer is associated with disease progression. Prostate 70: 1778-1787, 2010.

23. Lagerholm S, Lagerholm S, Dutta S and Nair P: Non-Invasive detection of c-myc p64, c-myc p67 and c-erbb-2 in colorectal cancer. Scand J Gastroenterol 40: 1343-1350, 2005.

24. Ozer HG, El-Gamal D, Powell B, Hing ZA, Blachly JS Harrington B, Mitchell S, Grieselhuber NR, Williams K, Lai TH, et al: BRD4 profiling identifies critical chronic lymphocytic leukemia oncogenic circuits and reveals sensitivity to PLX51107, a novel structurally distinct BET inhibitor. Cancer Discov 8: 458-477, 2018.

25. Erkes DA, Field CO, Capparelli C, Tiago M, Purwin TJ Chervoneva I, Berger AC, Hartsough EJ, Villanueva J and Aplin AE: The next-generation BET inhibitor, PLX51107, delays melanoma growth in a CD8-mediated manner. Pigment Cell Melanoma Res 32: 687-696, 2019.

26. Stubbs MC, Burn TC, Sparks R, Maduskuie T, Diamond S, Rupar M, Wen X, Volgina A, Zolotarjova N, Waeltz P, et al: The novel bromodomain and extraterminal domain inhibitor INCB054329 induces vulnerabilities in myeloma cells that inform rational combination strategies. Clin Cancer Res 25 300-311, 2019

27. Wilson AJ, Stubbs M, Liu P, Ruggeri B and Khabele D: The BET inhibitor INCB054329 reduces homologous recombination efficiency and augments PARP inhibitor activity in ovarian cancer. Gynecol Oncol 149: 575-584, 2018.

28. Yao Z, Yang S, Zhao H, Yang H and Jiang X: BET inhibitor I-BET151 sensitizes GBM cells to temozolomide via PUMA induction. Cancer Gene Ther 27: 226-234, 2019.

29. Guo NH, Zheng JF, Zi FM and Cheng J: I-BET151 suppresses osteoclast formation and inflammatory cytokines secretion by targetting BRD4 in multiple myeloma. Biosci Rep 39: BSR20181245, 2019

30. Wang C, Cigliano A, Jiang L, Li X, Fan B, Pilo MG, Liu Y, Gui B, Sini M, Smith JW, et al: 4EBP1/eIF4E and p70S6K/RPS6 axes play critical and distinct roles in hepatocarcinogenesis driven by AKT and N-Ras proto-oncogenes in mice. Hepatology 61: 200-213, 2015

31. Chao MW, Wang LT, Lai CY, Yang XM, Cheng YW, Lee KH, Pan SL and Teng CM: eIF4E binding protein 1 expression is associated with clinical survival outcomes in colorectal cancer. Oncotarget 6: 24092-24104, 2015

32. William M, Leroux LP, Chaparro V, Lorent J, Graber TE, M'Boutchou MN, Charpentier T, Fabié A, Dozois CM, Stäger S, et al: eIF4E-Binding proteins 1 and 2 limit macrophage anti-inflammatory responses through translational repression of IL-10 and cyclooxygenase-2. J Immunol 200: 4102-4116, 2018

33. Bao Y, Wu X, Chen J, Hu X, Zeng F, Cheng J, Jin H, Lin X and Chen LF: Brd4 modulates the innate immune response through mnk2-eIF4E pathway-dependent translational control of IkB $\alpha$. Proc Natl Acad Sci USA 114: E3993-E4001, 2017.

34. Batool A, Majeed ST, Aashaq S, Majeed R, Shah G, Nazir N and Andrabi KI: Eukaryotic initiation factor 4E (eIF4E) sequestration mediates $4 \mathrm{E}-\mathrm{BP} 1$ response to rapamycin. Int $\mathrm{J}$ Biol Macromol 125: 651-659, 2019.
35. Modrak-Wojcik A, Gorka M, Niedzwiecka K, Zdanowski K, Zuberek J, Niedzwiecka A and Stolarski R: Eukaryotic translation initiation is controlled by cooperativity effects within ternary complexes of 4E-BP1, eIF4E, and the mRNA 5' cap. FEBS Lett 587: 3928-3934, 2013.

36. Gao W, Lam JW, Li JZ, Chen SQ, Tsang RK, Chan JY and Wong TS: MicroRNA-138-5p controls sensitivity of nasopharyngeal carcinoma to radiation by targeting EIF4EBP1. Oncol Rep 37: 913-920, 2017.

37. Cha YL, Li PD, Yuan LJ, Zhang MY, Zhang YJ, Rao HL, Zhang HZ, Zheng XF and Wang HY: EIF4EBP1 overexpression is associated with poor survival and disease progression in patients with hepatocellular carcinoma. PLoS One 10: e117493, 2015.

38. Wang Z, Feng X, Molinolo AA, Martin D, Vitale-Cross L, Nohata N, Ando M, Wahba A, Amornphimoltham P, Wu X, et al: $4 \mathrm{E}-\mathrm{BP} 1$ is a tumor suppressor protein reactivated by mTOR inhibition in head and neck cancer. Cancer Res 79: 1438-1450, 2019.

39. Furic L, Rong L, Larsson O, Koumakpayi IH, Yoshida K, Brueschke A, Petroulakis E, Robichaud N, Pollak M, Gaboury LA, et al: EIF4E phosphorylation promotes tumorigenesis and is associated with prostate cancer progression. Proc Natl Acad Sci USA 107: 14134-14139, 2010.

40. D'Abronzo LS and Ghosh PM: EIF4E phosphorylation in prostate cancer. Neoplasia 20: 563-573, 2018.

41. Lee M, Kim EJ and Jeon MJ: MicroRNAs 125a and 125b inhibi ovarian cancer cells through post-transcriptional inactivation of EIF4EBP1. Oncotarget 7: 8726-8742, 2016.

42. Livak KJ and Schmittgen TD: Analysis of relative gene expression data using real-time quantitative PCR and the 2(-Delta Delta C(T)) method. Methods 25: 402-408, 2001.

43. Delmore JE, Issa GC, Lemieux ME, Rahl PB, Shi J, Jacobs HM, Kastritis E, Gilpatrick T, Paranal RM, Qi J, et al: BET bromodomain inhibition as a therapeutic strategy to target c-myc. Cell 146: 904-917, 2011

44. Bandopadhayay P, Bergthold G, Nguyen B, Schubert S, Gholamin S, Tang Y, Bolin S, Schumacher SE, Zeid R, Masoud S, et al: BET bromodomain inhibition of MYC-amplified medulloblastoma. Clin Cancer Res 20: 912-925, 2014.

45. Coudé MM, Braun T, Berrou J, Dupont M, Bertrand S, Masse A, Raffoux E, Itzykson R, Delord M, Riveiro ME, et al: BET inhibitor OTX015 targets BRD2 and BRD4 and decreases c-MYC in acute leukemia cells. Oncotarget 6: 17698-17712, 2015.

46. Baker EK, Taylor S, Gupte A, Sharp PP, Walia M, Walsh NC, Zannettino AC, Chalk AM, Burns CJ and Walkley CR: BET inhibitors induce apoptosis through a MYC independent mechanism and synergise with CDK inhibitors to kill osteosarcoma cells. Sci Rep 5: 10120, 2015.

47. Shao Q, Kannan A, Lin Z, Stack BJ, Suen JY and Gao L: BET protein inhibitor JQ1 attenuates myc-amplified MCC tumor growth in vivo. Cancer Res 74: 7090-7102, 2014.

48. Shi J, Wang Y, Zeng L, Wu Y, Deng J, Zhang Q, Lin Y, Li J, Kang T, Tao M, et al: Disrupting the interaction of BRD4 with diacetylated twist suppresses tumorigenesis in basal-like breast cancer. Cancer Cell 25: 210-225, 2014.

49. Takashima Y, Kikuchi E, Kikuchi J, Suzuki M, Kikuchi H, Maeda M, Shoji T, Furuta M, Kinoshita I, Dosaka-Akita H, et al: Bromodomain and extraterminal domain inhibition synergizes with WEE1-inhibitor AZD1775 effect by impairing non-homologous end joining and enhancing DNA damage in non-small cell lung cancer. Int J Cancer 15: 1114-1124, 2019.

50. Wang SS, Chen G, Li SH, Pang JS, Cai KT, Yan HB, Huang ZG and He RQ: Identification and validation of an individualized autophagy-clinical prognostic index in bladder cancer patients. Onco Targets Ther 12: 3695-3712, 2019.

51. Wei W, Cao W, Zhan Z, Yan L, Xie Y and Xiao Q: MiR-1284 suppresses gastric cancer progression by targeting EIF4A1. Onco Targets Ther 12: 3965-3976, 2019.

52. Xing ZY, Wang Y, Cheng L, Chen J, He XZ and Xing W: Bromodomain-Containing protein 4 (BRD4) inhibition sensitizes palomid 529-induced anti-renal cell carcinoma cell activity in vitro and in vivo. Cell Physiol Biochem 50: 640-653, 2018.

53. Liao S, Maertens O, Cichowski K and Elledge SJ: Genetic modifiers of the BRD4-NUT dependency of NUT midline carcinoma uncovers a synergism between BETis and CDK4/6is. Genes Dev 32: 1188-1200, 2018.

54. Tan Y, Wang L, Du Y, Liu X, Chen Z, Weng X, Guo J, Chen H, Wang $M$ and Wang X: Inhibition of BRD4 suppresses tumor growth in prostate cancer via the enhancement of FOXO1 expression. Int J Oncol 53: 2503-2517, 2018. 
55. Gao Z, Yuan T, Zhou X, Ni P, Sun G, Li P, Cheng Z and Wang X: Targeting BRD4 proteins suppresses the growth of NSCLC through downregulation of eIF4E expression. Cancer Biol Ther 19: 407-415, 2018

56. Hsu HS, Lin MH, Jang YH, Kuo TT, Liu CC and Cheng TH: The 4E-BP1/eIF4E ratio is a determinant for rapamycin response in esophageal cancer cells. J Thorac Cardiovasc Surg 149: 378-385, 2015.

57. Wang H, Liu Y, Ding J, Huang Y, Liu J, Liu N, Ao Y, Hong Y, Wang L, Zhang L, et al: Targeting mTOR suppressed colon cancer growth through 4EBP1/eIF4E/PUMA pathway. Cancer Gene Ther 27: 448-460, 2020.
58. Schwartz YB, Kahn TG, Stenberg P, Ohno K, Bourgon R and Pirrotta V: Alternative epigenetic chromatin states of polycomb target genes. PLoS Genet 6: e1000805, 2010.

59. Thieffry D and Sanchez L: Alternative epigenetic states understood in terms of specific regulatory structures. Ann N Y Acad Sci 981: 135-153, 2002.

(c) (i) $(9$ This work is licensed under a Creative Commons (c) At ${ }_{\mathrm{EY}}$ ND A Atribution-NonCommercial-NoDerivatives 4.0 International (CC BY-NC-ND 4.0) License. 